\title{
Examination of validity of a conditioned odor aversion (COA) procedure using low-dose of organic solvent as an applied procedure of the conditioned taste aversion
}

\author{
Rieko HOJO ${ }^{1 *}$, Mitsutoshi TAKAYA ${ }^{2}$, Akinori YASUDA ${ }^{1}$, \\ Masao TSUCHIYA ${ }^{3}$ and Yasutaka OGAWA ${ }^{4}$
}

\begin{abstract}
${ }^{1}$ Industrial Toxicology and Health Effects Research Group, Japan Organization of Occupational Health and Safety, National Institute of Occupational Safety and Health, Japan

${ }^{2}$ Work Environment Research Group, Japan Organization of Occupational Health and Safety, National Institute of Occupational Safety and Health, Japan

${ }^{3}$ Occupational Stress Research Group, Japan Organization of Occupational Health and Safety, National Institute of Occupational Safety and Health, Japan

${ }^{4}$ Health Service Facility for the Elderly Hasunehimawarienn, Japan
\end{abstract}

Received March 9, 2017 and accepted October 26, 2017

Published online in J-STAGE November 23, 2017

\begin{abstract}
Smell of very low dose of chemical might evoke subjective physical symptoms in human by some process of learning named the aversion conditioning. But few scientific evidences of the hypothesis have been reported so far. Validity of conditioned odor aversion (COA) using low-doses of organic solvent as odor conditioned stimulus (CS) was examined. In conditioning phase, waterdeprived male Sprague-Dawley rats were presented low, medium or high dose solution for 30 min followed by $0.3 \mathrm{M}$ Lithium Chloride ( $\mathrm{LiCl}$ ) solution or saline injection. The xylene solution and drink water were simultaneously provided on the next day as two-bottle test. Consumption of medium dose of xylene solution was significantly decreased in $\mathrm{LiCl}$ injection group as compared with saline group. There was no difference between $\mathrm{LiCl}$ and saline injected animals in low group. Animals in high dose did not access to xylene even on the conditioning. These results indicate that animals showed high sensitivity for discrimination against concentration of xylene and that the medium dose of xylene functioned as the CS. We concluded that the COA used in the present study may be one of useful procedures to investigate olfaction of animal.
\end{abstract}

Key words: Conditioned odor aversion (COA), Odor, Rat, Lithium chloride (LiCl), Xylene

\section{Introduction}

Health problems concerned about bad smell at workplace has changed recently. Though formerly main target

*To whom correspondence should be addressed.

E-mail: hojo@h.jniosh.go.jp

(C)2018 National Institute of Occupational Safety and Health was to prevent/manage exposures to high dose toxic chemicals contaminated in the workplace environment, now the issues are changed to control low dose indoor chemicals for making the workplace comfortable, or for preventing health problems ${ }^{1,2}$. Office environment is the major target of this issue, where most chemical exposures are by low dose inhalation and complaints are mainly from smell. The web investigation about the smell discomfort at workplace 
performed to 500 Japanese men and women of $20-50 \mathrm{yr}$ old working at office environment, reported that about 80 percent felt dissatisfaction against the body odor of the fellow workers ${ }^{3)}$.

When we look from public perspective, general market nowadays shows increasing interests to the products with odor, such as shampoos, softening agents for cloths, or incenses for relaxing ${ }^{4)}$. And there is growing number of people who have psychological and physiological complaints or displeasure against the smell with low doses of chemicals, which do not have toxic effects. For example, by the telephone survey to 1,000 or more people in the U.S., it was reported that $30.5 \%$ of participants have experienced irritation by fragrance from others, and 19\% have been worried about the health effects from aromatic compounds of others ${ }^{5}$. These results suggest that some odors can become stressor even if the concentrations are very ${ }^{l o w}{ }^{6}$. Furthermore, some studies pointed out that smell can induce not only stress but also illness ${ }^{6,7}$. Multiple chemical sensitivity $(\mathrm{MCS})^{8}$, which have been proposed to occur by exposure to extremely low-concentration of chemicals, and sick-building syndrome $(\mathrm{SBS})^{7}$, which is intimately related to low level exposure to workplace chemicals, are recognized as a health problem related to unpleasant smell, because appearance of sick conditions and exposure to unpleasant odors are closely connected in both cases ${ }^{2,7,9,10)}$. However the dispute on whether a cause is direct toxicities of chemical substances or a smell related psychological response is not yet settled.

Many volatile chemicals are sensed by their smell even though the level is under the Threshold Limited Values $(\mathrm{TLVs})^{11)}$. For example, TLV and odor threshold of toluene are 20 and $0.16 \mathrm{ppm}(\mathrm{v} / \mathrm{v})$, respectively, and those of xylene are 100 and $0.49 \mathrm{ppm}(\mathrm{v} / \mathrm{v})^{12)}$. In fact, some organic solvents including toluene and xylene are identified as causative agents of the $\mathrm{SBS}^{10)}$ and also, they are suspected to induce the $\mathrm{MCS}^{8}$. Some researchers pointed out that the health effects could appear by those chemicals with much lower level than the TLV if the occurrence of sickness is related to the smell of chemicals ${ }^{13)}$.

To promote the research on the health effects induced by smell, it is important to develop effective animal experiments that can evaluate the response of animals to the smell of chemicals at very low concentration level. Many animal studies reported about toxic effects of chemicals which have smells and a lot of scientific knowledge about them has been accumulated so far. However, there have been few animal studies that investigated health effects derived from smell itself. Because experiments using gas phase odorants were always faced to some physiological, procedural and mechanical difficulties. Habituation to the smell disturbs reproducibility; a certain level of dilution requires complicate procedure and measurement of extremely low concentration needs sophisticated analytical instruments. One of our authors intended to detect odor threshold value of toluene of mice by a toluene gas dilution technique. Although the detected concentration was not accurate because of the limitation of the dilution method, it was lower than $500 \mathrm{ppb}^{14,15)}$. In addition, it was reported that rats showed high sensitivity to organic solvent such as xylene under the conditioned odor aversion procedure even though the concentration was very low ${ }^{16)}$. In this paper, we will introduce a simple method to quantitatively determine the odor threshold level, but not the absolute value, using water solution.

Since the early works of Garcia and colleagues ${ }^{17)}$, the conditioned taste aversion (CTA), which is one of the classical conditionings, have extensively been used in a variety of situations ${ }^{18)}$. The CTA can be understood as the process of learning about the temporal and/or causal relationship between external (e.g., tastes or foods, and chemicals) and internal (e.g., emotional or physical changes) stimuli. In classical conditioning, the conditioned stimulus (CS) is a previously neutral stimulus that, after becoming associated with the unconditioned stimulus (US), eventually comes to trigger a conditioned response (CR). This process enables the organisms to use the appropriate preparatory set of responses before biologically significant events occur ${ }^{19)}$. The CTA is frequently used as a behavioral index of toxicosis of chemicals ${ }^{20,21)}$. The typical CTA phenomenon goes as follows. When an ingestion of tastant (e.g., saccharin, sucrose solutions, or appetizing food $)^{22-24)}$ or flavor stimulant (e.g., essences of vanilla, almond or orange $)^{25-27)}$ mixed water is followed by toxicosis induced by a drug, the consumption of tastant or flavor stimulant mixed water decrease $^{23,28,29)}$. In this associative learning paradigm, the CS is the gustatory (and/or olfactory) stimulus provided by the tastant or flavor stimulant and is assumed to have become associated with the aversive US that is the malaise induced by toxic agents ${ }^{30,31)}$. The CR is the suppression of CS inducing solution intake.

In the present study, we established a conditioned odor aversion (COA), which was a slightly modified procedure of the CTA, applied to investigate smell perception in rat. We investigated the COA response of animals, xylene in water solution as the odor $\mathrm{CS}$ and $\mathrm{LiCl}$ intra-peritoneal injection as adverse US. As a result, the COA responses were induced by the xylene level at which no gustatory 
response was observed. This result suggested that the olfactory of animal can be measured by the COA procedure.

\section{Methods}

\section{Experimental animals}

Male Sprague-Dawley rats, 4 wk of age, were purchased from Charles River (Yokohama, Japan). Each was housed in a suspended stainless-steel cage in a vivarium maintained at a temperature of $20^{\circ} \mathrm{C}$ with a $12: 12$ light cycle (8:00 - 20:00 was the light cycle). Food was available $a d$ libitum. After $5 \mathrm{~d}$ of acclimation, water deprivation procedure was started. During the water deprivation, water tubes connecting to the rat's home cage was opened from 16:00 for 60 min per day. After the 5-d of water deprivation, a bottle training was introduced. Animals were trained to drink from glass bottles for $60 \mathrm{~min}$ per day in their home cages for another $5 \mathrm{~d}$, and before the conditioning started animals were weighed and randomly allocated to six groups, those were three concentration groups with two US (lithium chloride [ $\mathrm{LiCl}]$ and saline) subgroups each consisted of six animals. The animals' weights were 139.4-198.1 g. During the experiment, we followed the guidelines for the care and use of laboratory animals set forth by the Institutional Animal Care and Use Committee of the Japan National Institute of Occupational Safety and Health. All efforts were made to minimize animal suffering and to use a minimal number of animals. Throughout the experiment, water consumption and the body weight of each rat were measured every day.

\section{Preparation of odor solution}

In the present study, low, medium and high concentrations of $p$-xylene (Wako, Japan, $>97 \%$ pure) solutions were provided as the CS. Drink water for rats was collected from animal vivarium and autoclaved with $121^{\circ} \mathrm{C}$ for $20 \mathrm{~min}$. The xylene solutions were made as follows: $100 \mu \mathrm{l}$ of pure $p$-xylene was diluted up to $1 \mathrm{~L}$ by filtered tap water in a glass bottle. Then $900 \mathrm{ml}$ of this solution was taken out from the bottom of the bottle using an extension tube of an intravenous drip and was used as the CS for a high dose group $(\mathrm{H})$. The $100 \mathrm{ml}$ of this solution was diluted to $1 \mathrm{~L}$ by filtered tap water. Then $900 \mathrm{ml}$ of the solution was taken out from the bottle with the extension tube. This solution was divided into $900 \mathrm{ml}$ and $100 \mathrm{ml}$ to use as the CS in the medium dose group (M) and for dilution, respectively. Finally, $100 \mathrm{ml}$ of this solution was diluted to $1 \mathrm{~L}$ by tap water and used for a low dose group
(L). All bottles were shaken overnight by a rotary shaker (NR-2; TAITEC, Japan) with $100 \mathrm{rpm}$ at the dilution and before providing to animals.

\section{Measurement of xylene concentration}

To examine the validity and the reliability of the dilution method in the present study, xylene solutions with low, medium and high doses for measurements were prepared by the same dilution method mentioned above. Absolute concentrations of solutions were measured by an ultra violet-visible (UV) spectrophotometer (UV-Vis-NIR Spectroscopy UV-3600; Shimadzu, Japan). All solutions were measured with automatic cell driver and spectrum cell design system equipped with quart cells with wavelength ranging $230-300 \mathrm{~nm}$, slit width $2.0 \mathrm{~nm}$, and sampling pitch $0.05 \mathrm{~nm}$. For the high concentration, three glass bottles, A, B and C with $958.76,952.05$ and $937.60 \mathrm{ml}$ of the drink water were prepared. Measured xylene 113, 113 and $91 \mu \mathrm{l}$ was added to bottles A, B and C, respectively. Calculated concentrations of bottles A, B and C were $117.86,118.69$ and $97.06 \mathrm{ppm}$, respectively. To make the medium concentration, $9.95 \mathrm{~g}$ of xylene solution was taken from the bottle B and mixed with $98.134 \mathrm{~g}$ of the drink water in the bottle D. Furthermore a 9.970-mg xylene solution, which was taken out from the bottle $\mathrm{D}$, was mixed together with $97.98 \mathrm{~g}$ of the drink water in the bottle $\mathrm{E}$ for making the low dose. Calculated concentrations of bottles $\mathrm{D}$ and $\mathrm{E}$ were 11.8 and $1.2 \mathrm{ppm}$, respectively. All bottles were shaken overnight with the shaker. Then bottles D and E were divided into three bottles each.

Each bottle was measured three times each on 0, 30, $60,90,120$ and $240 \mathrm{~min}$ after the solution preparation. As the experiment procedure was performed during 30-60 min after the solution preparation, measurement time was selected for comprising the whole experimental procedure. Average concentrations $( \pm \mathrm{SD})$ of three times were calculated and determined as measured concentrations. The average concentration on each time in each dose was compared with each calculated concentration which was set to 1 , expressing the relative concentration.

As standard solutions, xylene solutions diluted with distilled water were measured for acquiring calibration curve. In addition, to examine the validity and the conformity of doses of solutions which were used in the present study, changes of xylene concentration by time progress were calculated with a least square method. With this purpose, xylene concentrations at 120 and 240 min were also measured by the UV spectrophotometer. In the calculation, changes of concentrations in the solutions during 30-60 
min after the solution preparation, at which the actual experiment was induced, were obtained. Then maximum concentrations of xylene vapor in the nasal cavity of rats were calculated by evaporated volumes of xylene. Those concentrations might be consumed by rat in the experiment.

\section{The COA procedure}

The COA procedure was started when animals were 6 wk of age. It consisted of two phases. One was a conditioning and another was a two-bottle test. The conditioning started at 16:00. Animal could access to one of high, medium or low dose of xylene solution from a drink bottle for $30 \mathrm{~min}$. Then as the US, $0.3 \mathrm{M} \mathrm{LiCl}$ or the saline was intraperitoneally administered immediately after the 30 min-solution consumption. To avoid dehydration, usual drink water was given for $30 \mathrm{~min}$ to the animal $120 \mathrm{~min}$ after the US injection. On the next day of the conditioning, the two-bottle test was conducted. Both the conditioning and the two-bottle test were conducted in the home cage.

\section{Conditioning}

As US stimulus, $\mathrm{LiCl}$ (Wako, Japan, $>97 \%$ pure) was dissolved up to $0.3 \mathrm{M}$ by saline and intraperitoneally injected to animals in $\mathrm{LiCl}$ subgroup with $1 \mathrm{ml}$ of volume. To animals in the control group as a counterpart, $1 \mathrm{ml}$ of saline was administered. The conditioning was induced to all animals on the same day. Drink volume of the xylene solution of each animal was calculated by measuring the bottle after the conditioning. About two hours after the conditioning, all animals could access to a pre-weighted glass bottle filled with usual filtered drink water for 30 min. Animal cages were horizontally arranged on the same stage of a rack by the given concentration of xylene solution. Cages in each counterpart (saline injection) subgroup were placed above the $\mathrm{LiCl}$ groups. The order of cages was as follows; the first and the second stages contained the low dose groups. Medium dose groups were on the third and the fourth stages. Animal cages of the high dose group were located on the first and the second stages of the other rack. Orders of providing drink bottle and administration of injection were performed from the top to the bottom, from the left to the right, and from one to the other of the rack.

\section{Two-bottle test}

Twenty-four hours after the injection of the $\mathrm{LiCl}$ in the conditioning, a two-bottle test was conducted to assess the animals' preference over the xylene solution. In the test, one bottle filled with usual drink water and another bottle with xylene solutions were simultaneously provided for 30 min to animals in all groups. Each bottle was pre-weighed with a burette with a graduation of $0.01 \mathrm{ml}$. Consumption volume of the CS solution was divided by total liquid intake (volumes of xylene solution plus usual drink water), which was defined as the preference ratio (PR), according to the method described by Danilova and Hellekant ${ }^{32}$. When the PR was statistically smaller than that of the animal in the counterpart control group, we judged that the conditioning was established.

\section{Statistical analysis}

Body weights of animals on the first day of their arrival, on the third day of the acclimation, and days of the bottle training, on the conditioning and the two-bottle test in all groups were separately analyzed by one-way analysis of variance (ANOVA). The water consumptions of animals in all groups on the third day of the bottle training were analyzed by one-way ANOVA. In addition, PRs of animals in the low and the medium dose groups on days of the conditioning and the two-bottle test were analyzed by two-way ANOVA. Main effect was the injections (saline and $\mathrm{LiCl}$ ) and the CS (doses), and repeated factor was the experimental procedures (conditioning and test). While animals in both saline and $\mathrm{LiCl}$ injection subgroups of the high dose group did not access to the xylene solution at all, the PR and the total liquid consumption in this group were not statistically analyzed. Absolute total liquid intakes on the conditioning and the two-bottle test were analyzed by one-way ANOVA in all xylene concentration groups. In consideration of the position effect of a cage of the rack, direct comparison between xylene solutions was not performed. Post hoc comparisons were made with Dunnett's test following significant main ANOVA effects to determine which LiCL injection group was different from the control group. The level of statistical significance was set at $p<0.05$. Data are expressed as mean values \pm SE. All statistical analyses were performed with SPSS statistical package software ver. 19.0 (IBM, Chicago, USA).

\section{Results}

\section{Verification xylene concentration}

Relative concentrations of xylene solutions measured by the UV spectrophotometer were $0.66 \pm 0.006,1.11 \pm$ 0.005 , and $1.14 \pm 0.11$ in the low, the medium and the high concentration groups, respectively at the providing time to animals (30 min after preparation) (Table 1). However, 
Table 1. Relative Concentration of Xylene Solution on Time 0-240

\begin{tabular}{lccccc}
\hline \multirow{2}{*}{ Dose } & \multicolumn{5}{c}{ Time (min.) } \\
\cline { 2 - 6 } & 0 & 30 & 60 & 120 & 240 \\
\hline High & $1.033 \pm 0.06$ & $1.138 \pm 0.11$ & $1.135 \pm 0.11$ & $1.067 \pm 0.11$ & $1.073 \pm 0.08$ \\
Medium & $1.044 \pm 0.05$ & $1.102 \pm 0.00$ & $1.025 \pm 0.03$ & $0.869 \pm 0.06$ & $0.681 \pm 0.04$ \\
Low ${ }^{*}$ & $1.338 \pm 0.17$ & $0.655 \pm 0.06$ & $0.702 \pm 0.24$ & $1.272 \pm 0.01$ & $0.878 \pm 0.34$ \\
\hline
\end{tabular}

Relative concentrations of xylene solutions with low, medium and high doses on time 0, 30, 60, 120 and 240 ( $\mathrm{min}$.), which were compared with the calculated concentration which was set to 1 . Xylene solutions for measurements were prepared by the same dilution method in the present study. Absolute concentrations of solutions were measured by an ultra violet-visible (UV) spectrophotometer (UV-Vis-NIR Spectroscopy UV-3600; Shimadzu, Japan). All solutions were shaken overnight and measured with automatic cell driver and spectrum cell design system equipped with quart cells with wavelength ranging $230-300 \mathrm{~nm}$, slit width $2.0 \mathrm{~nm}$, and sampling pitch $0.05 \mathrm{~nm}$.

*Although concentrations of the Low dose were detected, they were judged as reference values because they were below a determination limit.

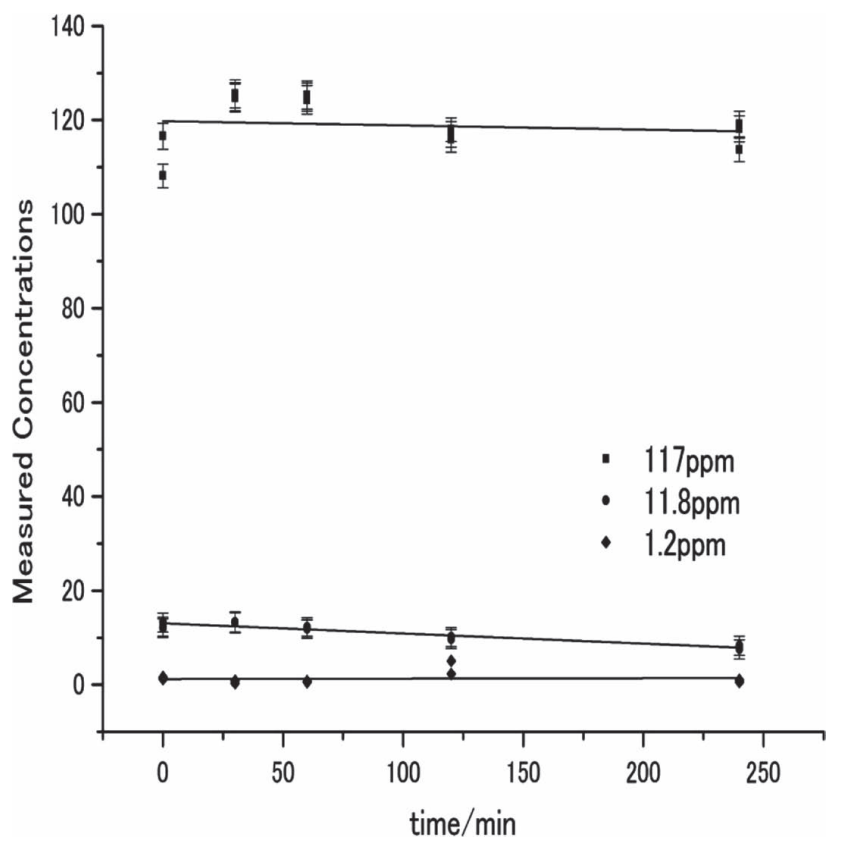

Fig. 1. Concentration changes of xylene by the time progress.

Concentrations of measured xylene solutions by the UV spectrophotometer at $0,30,60,120$ and $240 \mathrm{~min}$ after the solution preparation. Horizontal axis means time/min, vertical axis means preference ratio of xylene solution calculated as follows; the volume consumed from the bottles containing the xylene solution was divided by all drink consumption (the drink volume of solution of xylene plus usual drink water).The medium and the low dose solutions were diluted from the high dose solution with the same method as the conditioning and two-bottle test in the present study. Expected concentrations of the high, the medium and the low were $117,11.8$ and $1.2 \mathrm{ppm}$, respectively. Lines on the top, the middle and the bottom mean approximate expressions of the high, the medium and the low dose. $\mathbf{m}$; high dose, $\bullet$; medium dose, $\bullet$; low dose. Each concentration is expressed as means $\pm \mathrm{SD}$. since the value of the low dose was below the minimum limit of detection, it was considered as a reference value. As shown in Fig. 1, the decrease of concentration of the measured solution by time progress showed a linear fashion in each group. Changes of xylene concentrations by time progress calculated with a least squares method in the high and the medium doses were expressed as these approximate expressions as follows;

$Y=-0.012 x+120.60$ (for the high dose group)

$Y=-0.022 x+13.08$ (for the medium dose group)

$\mathrm{Y}$ and $\mathrm{x}$ mean concentration and time progress, respectively.

Decrease rates were very small in all groups even $4 \mathrm{~h}$ after the solution preparation.

We calculated concentrations of xylene vapor in the high and the middle doses were about 23.04 and $2.30 \mathrm{ppm}$ $(\mathrm{v} / \mathrm{v})$, respectively. Although the calculated concentration of the low dose was $0.23 \mathrm{ppm}(\mathrm{v} / \mathrm{v})$, it was taken as reference value because the value was below the minimum limit of detection.

\section{COA response}

Body weights of animal on all dates were not significantly different between the control and $\mathrm{LiCl}$ subgroups in each xylene concentration (data not shown).

There was no significant difference in water consumptions on the third day of bottle training among groups $(\mathrm{F}=1.367, p=0.255$, Table 2-A). PRs on the day of conditioning were not different between saline and $\mathrm{LiCl}$ injection in both the low and the high xylene solution groups (Table $2-B)$. On the other hand, two-way ANOVA revealed significant effects of injection $(\mathrm{F}=12.616, p<0.001)$ and inter- 
Table 2. Liquid intakes of animals on the third day of bottle training, conditioning and two-bottle test.

(A) Liquid intakes of animals on the third day of bottle training.

\begin{tabular}{|c|c|c|}
\hline \multirow{2}{*}{$\begin{array}{l}\text { Xylene solution } \\
\quad(\mathrm{ppm})\end{array}$} & \multirow{2}{*}{$\begin{array}{l}\text { Injection } \\
(\mathrm{ml})\end{array}$} & Bottle training \\
\hline & & Water (ml) \\
\hline \multirow{2}{*}{1} & Saline & $19.9 \pm 6.0$ \\
\hline & $\mathrm{LiCl}$ & $22.6 \pm 4.7$ \\
\hline \multirow{2}{*}{10} & Saline & $15.4 \pm 3.0$ \\
\hline & $\mathrm{LiCl}$ & $15.8 \pm 3.7$ \\
\hline \multirow{2}{*}{100} & Saline & $17.4 \pm 5.8$ \\
\hline & $\mathrm{LiCl}$ & $16.0 \pm 6.2$ \\
\hline
\end{tabular}

(B) Liquid intakes of animals on the day of conditioning procedure.

\begin{tabular}{cccccc}
\hline \multirow{2}{*}{$\begin{array}{c}\text { Xylene solution } \\
(\mathrm{ppm})\end{array}$} & Injection & \multicolumn{4}{c}{ Conditioning procedure } \\
\cline { 3 - 6 } & & Xylene $(\mathrm{ml})$ & Water $(\mathrm{ml})$ & Total $(\mathrm{ml})$ & Preference ratio \\
\hline \multirow{2}{*}{1} & Saline & $7.5 \pm 7.9$ & $10.3 \pm 6.0$ & $17.8 \pm 8.7$ & $0.4 \pm 0.3$ \\
& $\mathrm{LiCl}$ & $5.7 \pm 5.7$ & $7.3 \pm 6.0$ & $12.9 \pm 8.5$ & $0.5 \pm 0.3$ \\
\hline \multirow{2}{*}{10} & Saline & $12.1 \pm 9.9$ & $15.2 \pm 8.1$ & $27.3 \pm 14.1$ & $0.4 \pm 0.2$ \\
& LiCl & $5.9 \pm 5.1^{*}$ & $13.0 \pm 4.1$ & $18.9 \pm 7.7^{*}$ & $0.3 \pm 0.2$ \\
\hline \multirow{2}{*}{100} & Saline & $0.0 \pm 0.0$ & $17.8 \pm 5.0$ & $17.8 \pm 5.0$ & $0.0 \pm 0.0$ \\
& LiCl & $0.0 \pm 0.0$ & $16.4 \pm 7.0$ & $16.4 \pm 7.0$ & $0.0 \pm 0.0$ \\
\hline
\end{tabular}

(C) Liquid intakes of animals on the day of two-bottle test.

\begin{tabular}{cccccc}
\hline \multirow{2}{*}{$\begin{array}{c}\text { Xylene solution } \\
(\mathrm{ppm})\end{array}$} & Injection & \multicolumn{4}{c}{ Two-bottle test } \\
\cline { 3 - 6 } & & Water $(\mathrm{ml})$ & Xylene $(\mathrm{ml})$ & Total $(\mathrm{ml})$ & Preference ratio \\
\hline \multirow{2}{*}{1} & Saline & $8.5 \pm 3.8$ & $8.0 \pm 5.0$ & $16.5 \pm 4.0$ & $0.5 \pm 0.2$ \\
& LiCl & $9.3 \pm 7.6$ & $6.8 \pm 5.5$ & $16.1 \pm 5.2$ & $0.4 \pm 0.4$ \\
\hline \multirow{2}{*}{10} & Saline & $12.0 \pm 3.0$ & $13.5 \pm 2.3$ & $25.5 \pm 3.5$ & $0.5 \pm 0.1$ \\
& LiCl & $17.8 \pm 5.0$ & $2.3 \pm 1.7^{*}$ & $20.1 \pm 5.7$ & $0.1 \pm 0.1$ \\
\hline \multirow{2}{*}{100} & Saline & $13.4 \pm 6.7$ & $0.0 \pm 0.0$ & $13.4 \pm 6.7$ & $0.0 \pm 0.0$ \\
& LiCl & $9.8 \pm 7.2$ & $0.0 \pm 0.0$ & $9.8 \pm 7.3$ & $0.0 \pm 0.0$ \\
\hline
\end{tabular}

Liquid intakes ( $\mathrm{ml}$ ) of animals $(\mathrm{A})$ on the third day of bottle training, on days of (B) conditioning procedure and $(\mathrm{C})$ two-bottle test. Group means $\pm \mathrm{SD}$ of water consumptions (ml) on the third day of the bottle training, conditioning and two-bottle test were indicated. Also xylene consumptions $(\mathrm{ml})$ on the conditioning and two-bottle test were shown with Group means \pm SD. In addition, preference ratios on conditioning and two-bottle test were indicated. The low, the medium and the high dose groups provided expected concentrations 1, 10 and $100 \mathrm{ppm}$ xylene solutions, respectively. The numbers of animals in the low, medium and high dose groups were 12. In each group there were two subgroups, injected $1 \mathrm{ml}$ of saline $(\mathrm{n}=6)$ and $\mathrm{LiCl}(\mathrm{n}=6)$. The concentration of $\mathrm{LiCl}$ diluted with saline was $0.3 \mathrm{M}$. *means $p<0.05$ (vs. saline injection animals in the same group).

action of injection $\times \mathrm{CS}(\mathrm{F}=10.082, p<0.005)$ in $\mathrm{PR}$ on the day of the two-bottle test (Table 2-C). A marginally significant effect of CS was also emerged $(\mathrm{F}=3.979, p=0.052)$ in the PR. There were significant differences in the total liquid intake on days of the conditioning and the test among groups, showing effects of injection $(\mathrm{F}=10.649, p<0.001)$ and concentration $(\mathrm{F}=18.310, p<0.001)$. Also, a marginally significant interaction effect of US $\times$ experimental procedure revealed $(\mathrm{F}=2.542, p=0.083)$. Post hoc test revealed that animals in the $\mathrm{LiCl}$ injection subgroup drank significantly smaller amount of liquid as compared with than that of animals in saline injection subgroup.

\section{Discussion}

In the present study, we examined the validity of the COA procedure in rat using odor stimulus. We focused on the discrimination sensitivity of animals against low doses 
of organic solvent and examined the function of odor of xylene as the CS under the procedure.

As the xylene consumption was significantly lowered as compared with that of control, animals injected $0.3 \mathrm{M} \mathrm{LiCl}$ in the medium dose group might recognize the difference between usual drink water and medium dose of the xylene solution functioned as the CS. Animal in the low dose group did not distinguish water and xylene solution. In the high dose group, since animals did not drink xylene solution even on the day of conditioning, they might disgust and avoid the solution because of the smell. These results imply that 0.86 (low dose) ppm was too low and $86 \mathrm{ppm}$ (high dose) was too high to establish the COA in the present study and that the threshold for establishment of the conditioning using xylene as the odor CS may exist around $8.6 \mathrm{ppm}$. Though the value was relative one, the threshold of xylene was determined with the procedure established in the present study. As we thought that concentration of xylene in the bottle space was almost equal to concentration of xylene in nasal cavity of rat, xylene concentrations in bottle spaces were calculated, assuming that all the xylene in solution volatilized to the bottle space. Therefore, calculated values were thought as maximum concentration. It was considered that actual xylene concentrations in bottle spaces were far lower than calculated values. In addition, solution concentration in each dose group at time 0 was almost the same as the assumed concentration, and xylene in solution was hardly decreasing in time progress. Threshold of xylene, $2.30 \mathrm{ppm}$, is higher than that of toluene as compared with the result of toluene threshold determined by Hojo et al. ${ }^{14)}$. While methodologies of calculation of concentration were different, it is difficult to direct comparison.

In human, the olfactory threshold of xylene is 0.05 $\mathrm{ppm}$, on the other hand, calculated concentration of high, medium and low dose groups were 23, 2.3 and $0.23 \mathrm{ppm}$, respectively. So we concluded that the conditioning procedure using odor stimulus instead of taste as the CS is a useful tool for examining preference or aversion of chemicals.

The xylene solution was diluted with usual drink water by the method employed in the present study. Although it was possible that the drink water contained some small amount of xylene, we used the drink water because the solution had to be consumed by animal. As the purpose of this study was to make rats consume xylene solutions and distinguish each dose, the control of concentration was not regarded as the most important issue. As a result, rats showed a different response to each concentration. In addition, since the concentration in the high dose was thought to be stable the most among groups, the concentration in the head space of the bottle during 30-60 min after the solution making was calculated. Xylene solutions diluted with the method in the present study measured by the UV spectrophotometer were approximately about $1 / 10$ and $1 / 100$ of the highest dose, respectively. Therefore, change of concentration of xylene solution in each dose group by the time process is thought negligible. Although concentration measured by the spectrophotometer in each dose group was not the same as the expected one, we thought that the range of concentrations from low and high doses were broad enough to be able to distinguish as different dose for rats. Taken together, we concluded that the diluted method used in the present study did not disturb the purpose of the present study, and that animals discriminated the difference of concentration of xylene because of the different response to each dose. These results implied that xylene can be a useful stimulus as the CS even if it was used as solution under the COA procedure.

The concentrations of xylene used in the present study were thought to be extremely low as compared with a number of animal studies using xylene as a carcinogen ${ }^{33,34)}$. Therefore, it is thought that the conditioned response (avoid medium dose of xylene solution) in the medium group of the present study was caused by the effect of the $\mathrm{COA}$, not toxic effect or addiction of the xylene itself. In addition, as the result revealed that sensitivity to discriminate function against organic solvents in rat was quite high, the COA in the present study would be able to apply to other organic solvent discrimination.

Previous experimental animal studies have reported that odor aversions were weaker than taste aversion ${ }^{35,36)}$. However, results in the present study indicated that low level of odor stimulus (xylene) functions CS under conditioned adverse learning. It is not surprising because previous studies reported that animals rapidly learn to avoid smells associated with malaise ${ }^{37,38)}$ and discrimination ability of mice against toluene was more than 100 times as compared with human ${ }^{14)}$. Therefore, we concluded that animals showed high sensitivity for discrimination against concentration of xylene and that xylene functioned as the CS. Though we measured concentration of xylene in the empty space of the drink bottle, actual xylene concentration in nasal cavity of rat should be measured for determining threshold of xylene.

Olfactory stimulation with toluene, xylene and other organic solvents elicit a bust of beta-frequency (15-30 $\mathrm{Hz}$ ) electroencephalogram activity (fast waves) in the dentate gyrus and olfactory bulb of male rats ${ }^{39,40)}$. The area 
is elicited by smells of predators, but not other odorous substances including food, rat vaginal secretions and rat excrement. Usually, xylene solution is noxious, at least not the pleasurable substance for rats. It is noteworthy that the COA was established even if noxious organic solvent was used as the CS. It may be possible to determine effectual olfactory thresholds of unknown or disgust odor using animals.

In the present study, because a chemical characteristic of xylene is insoluble in water and the concentration of xylene was below the detection limit value in the manufacture method in this experiment, xylene solution was defined as the 'odor' stimulus instead of the taste. However, there were some concerns by using xylene in solution as odor CS. Because xylene is one of the most common organic solvents in workplace, and the common route of exposure is inhalation, xylene gas would be the suitable for the aim of the present study. If we used organic solvents as gas, control of concentration, especially in the case of using very low dose of solvent, is problematic. In the present study, we focused on the validity of the COA procedure using very low dose of organic solvent as the CS. Therefore, it is thought that the COA used in the present study may be one of useful procedures to investigate olfaction of animal. At the same time, a method of conditioning which used VOCs as gas stimulus should be established and examined in the further experiment. If the odor stimulus would be presented as gas, we can show the stimulus as odor. We would like to examine the conditioning which examine the sense-of-smell using odor stimulus from now on.

\section{Conclusions}

Animals might discriminate against low, medium and high dose xylene solutions. Animals may have high sensitivity to odor of organic solvents. At least medium dose of xylene solution functioned as the conditioned odor stimulus. We concluded that the COA used in the present study may be one of useful procedures to investigate olfaction of animal.

\section{Acknowledgement}

We are deeply grateful to Dr. Seiichiro Kanno whose comments and suggestions were of inestimable value for our study. The present study was supported by grant-inaid for fundamental research from the National Institute of Occupational Safety and Health, Japan (N-F22-12).

The authors declare no competing financial interests.

\section{References}

1) Wolkoff P (2013) Indoor air pollutants in office environments: assessment of comfort, health, and performance. Int J Hyg Environ Health 216, 371-94. [Medline] [CrossRef]

2) Wolkoff P, Wilkins CK, Clausen PA, Nielsen GD (2006) Organic compounds in office environments - sensory irritation, odor, measurements and the role of reactive chemistry. Indoor Air 16, 7-19. [Medline] [CrossRef]

3) Seiren Inc J (2014) Deoest [in Japanese; online 14 April 2014].

4) AEAJ News release (2013) Research report about aroma market. AEAJ (Aroma Environment Association of Japan).

5) Caress SM, Steinemann AC (2009) Prevalence of fragrance sensitivity in the American population. J Environ Health 71, 46-50. [Medline]

6) Buckley DA, Rycroft RJ, White IR, McFadden JP (2002) Fragrance as an occupational allergen. Occup Med (Lond) 52, 13-6. [Medline] [CrossRef]

7) Letz GA (1990) Sick building syndrome: acute illness among office workers - the role of building ventilation, airborne contaminants and work stress. Allergy Proc 11, 10916. [Medline] [CrossRef]

8) Sorg BA, Hochstatter T (1999) Behavioral sensitization after repeated formaldehyde exposure in rats. Toxicol Ind Health 15, 346-55. [Medline] [CrossRef]

9) Azuma K, Uchiyama I, Takano H, Tanigawa M, Azuma M, Bamba I, Yoshikawa T (2013) Changes in cerebral blood flow during olfactory stimulation in patients with multiple chemical sensitivity: a multi-channel near-infrared spectroscopic study. PLoS One 8, e80567. [Medline] [CrossRef]

10) Yoshida $T$, Ogawa $M$, Goto $H$, Ohshita $A$, Kurose $N$, Yokosawa F, Hirata M, Endo Y (2011) Clinical findings of the patients with sick building syndrome and the results of environmental measurement. Sangyo Eiseigaku Zasshi 53, 25-32 (in Japanese). [Medline] [CrossRef]

11) ACGIH (American Conference of Governmental Industrial Hygienists) (2001) Documentation of the Threshold Limit Values and Biological Exposure Indices, 7th Ed. USA.

12) EPA (1990) Interim method for development of in halation reference doses. U.S. Environmental Protection Agency. EPA/600/8-90/066A.

13) Paustenbach DJ, Gaffney SH (2006) The role of odor and irritation, as well as risk perception, in the setting of occupational exposure limits. Int Arch Occup Environ Health 79, 339-42. [Medline] [CrossRef]

14) Hojo R, Kurokawa $Y$, Tsukahara S, Nakajima D, Fujimaki H (2008) Evaluation of olfactory detection threshold of odor in mice using operant learning procedure. Journal of Japan Association on Odor Environment 39, 186-91(in Japanese). [CrossRef]

15) Hojo R, Sakamoto T, Ogawa Y, Kurokawa Y (2011) Comfortability and odor at office Environment. -Establishment of a procedure for odor screening test in mice against VOCs and MVOCs. J of Occupational Safety and Health 4, 51-6 
(in Japanese). [CrossRef]

16) Hojo R, Yanagiba $Y$, Takaya M, Tsuchiya M, Yasuda A, Ogawa Y (2015) Conditioned taste aversion with low-dose organic solvents. Journal of Occupational Safety and Health 8, 83-90. [CrossRef]

17) Garcia J, Koelling RA (1966) Relation of cue to consequence in avoidance learning. Psychon Sci 4, 123-4. [CrossRef]

18) Kiefer SW (1985) Neural mediation of conditioned food aversions. Ann N Y Acad Sci 443, 100-9. [Medline] [CrossRef]

19) Rescorla RA (2003) Contemporary study of Pavlovian conditioning. Span J Psychol 6, 185-95. [Medline] [CrossRef]

20) Hunt T, Amit $Z$ (1987) Conditioned taste aversion induced by self-administered drugs: paradox revisited. Neurosci Biobehav Rev 11, 107-30. [Medline] [CrossRef]

21) Wesierska M, Buresová O, Bures J (1988) Differential effect of prior paradoxical sleep deprivation on conditioned taste aversion, neophobia and attenuation of neophobia to solid food in rats. Behav Brain Res 27, 115-21. [Medline] [CrossRef]

22) Bignami G, Giardini V, Scorrano M (1985) Behaviorally augmented versus other components in organophosphate tolerance: the role of reinforcement and response factors. Fundam Appl Toxicol 5, S213 -24. [Medline] [CrossRef]

23) Garcia J, Kimeldorf DJ, Koelling RA (1955) Conditioned aversion to saccharin resulting from exposure to gamma radiation. Science 122, 157-8. [Medline]

24) Smith ME, Norgren R, Grigson PS (2004) A mixed design reveals that glucose moieties facilitate extinction of a conditioned taste aversion in rats. Learn Behav 32, 454-62. [Medline] [CrossRef]

25) Kitagaki-Ogawa H, Matsumoto I, Seno N, Takahashi N, Endo S, Arata Y (1986) Characterization of the carbohydrate moiety of Clerodendron trichotomum lectins. Its structure and reactivity toward plant lectins. Eur J Biochem 161, 779-85. [Medline] [CrossRef]

26) Ralphs MH, Provenza FD, Wiedmeier RD, Bunderson FB (1995) Effects of energy source and food flavor on conditioned preferences in sheep. J Anim Sci 73, 1651-7. [Medline] [CrossRef]

27) Rusiniak KW, Garcia J, Palmerino CC, Cabral RJ (1983) Developmental flavor experience affects utilization of odor, not taste in toxiphobic conditioning. Behav Neural Biol 39, 160-80. [Medline] [CrossRef]

28) Garcia J, Ervin FR (1968) Appetites, aversions, and addic- tions: a model for visceral memory. Recent Adv Biol Psychiatry 10, 284-93. [Medline] [CrossRef]

29) Revusky SH, Bedarf EW (1967) Association of illness with prior ingestion of novel foods. Science 155, 219-20. [Medline] [CrossRef]

30) Schou M (1958) Lithium studies. 1. Toxicity. Acta Pharmacol Toxicol (Copenh) 15, 70-84. [Medline] [CrossRef]

31) Schou M (1958) Lithium studies. 2. Renal elimination. Acta Pharmacol Toxicol (Copenh) 15, 85-98. [Medline] [CrossRef]

32) Danilova V, Hellekant G (2004) Sense of taste in a New World monkey, the common marmoset. II. Link between behavior and nerve activity. J Neurophysiol 92, 1067-76. [Medline] [CrossRef]

33) IARC (1989) (International Agency for Research on Cancer)author $\leftarrow$ Xylene. In: Re-evaluation of some organic chemicals, hydrazine and hydrogen peroxide. IARC Monogr Eval Carcinog Risks Hum 71, 1189-208.

34) National Toxicology Program (1986) NTP Toxicology and Carcinogenesis Studies of Xylenes (Mixed) $(60 \%$ m-Xylene, 14\% p-Xylene, 9\% o-Xylene, and 17\% Ethylbenzene) (CAS No. 1330-20-7) in F344/N Rats and B6C3F1 Mice (Gavage Studies). Natl Toxicol Program Tech Rep Ser 327, 1-160. [Medline]

35) Bermudez-Rattoni F, Forthman DL, Sanchez MA, Perez JL, Garcia J (1988) Odor and taste aversions conditioned in anesthetized rats. Behav Neurosci 102, 726-32. [Medline] [CrossRef]

36) Capaldi ED, Hunter MJ, Privitera GJ (2004) Odor of taste stimuli in conditioned "taste" aversion learning. Behav Neurosci 118, 1400-8. [Medline] [CrossRef]

37) Batsell WR, Best MR (1992) Variations in the retention of taste aversions: Evidence for retrieval competition. Anim Learn Behav 20, 146-59. [CrossRef]

38) Batsell WR, Best MR (1993) One bottle too many? Method of testing determines the detection of overshadowing and retention of taste aversions. Anim Learn Behav 21, 154-8. [CrossRef]

39) Chapman CA, Xu Y, Haykin S, Racine RJ (1998) Beta-frequency $(15-35 \mathrm{~Hz})$ electroencephalogram activities elicited by toluene and electrical stimulation in the behaving rat. Neuroscience 86, 1307-19. [Medline] [CrossRef]

40) Heale VR, Vanderwolf CH, Kavaliers M (1994) Components of weasel and fox odors elicit fast wave bursts in the dentate gyrus of rats. Behav Brain Res 63, 159-65. [Medline] [CrossRef] 